\title{
Classical lissencephaly syndromes: does the face reflect the brain?
}

\author{
J E Allanson, D H Ledbetter, W B Dobyns
}

Children's Hospital of Eastern Ontario and University of Ottawa, Ottawa, Ontario, Canada

J E Allanson

Center for Medical Genetics, University of Chicago, Chicago, IL, USA

D H Ledbetter

University of

Minnesota,

Minneapolis, MN, USA

W B Dobyns

Correspondence to:

Dr Allanson, Department of Genetics, Children's Hospital of Eastern Ontario, 401 Smyth Road, Ottawa, ON K1H 8L1, Canada.

Received 30 January 1998 Revised version accepted for publication 20 April 1998

\begin{abstract}
Both Miller-Dieker syndrome and isolated lissencephaly sequence are associated with classical lissencephaly. Both have been shown to be associated with deletions and mutations in LIS1 on 17p. Traditionally, the two disorders have been distinguished by the presence of a characteristic facial appearance in Miller-Dieker syndrome. The forehead is tall and prominent and may have vertical furrowing. There is narrowing at the temples. Eyes are widely spaced with upward slanting fissures. The nose is very short with anteverted nares. The upper lip is long, wide, and thick. The ears may have minor flattening of the helices. By contrast, these features are not seen in isolated lissencephaly sequence.

We have measured five children with Miller-Dieker syndrome (MDS) and 25 children and adolescents with isolated lissencephaly sequence (ILS). Z score (standard deviation score) pattern profiles have been formulated and compared. Patients with ILS at all ages show reduced head circumference, a round head, and a wide and flat face with a broad nose and widely spaced eyes. The most unexpected finding is the similarity of pattern profiles of ILS and MDS in the age group 6 months to 4 years. Correlation coefficient is 0.812 $(p<0.001)$. In MDS there are a few distinguishing features, including brachy-
\end{abstract}

cephaly, a slightly wider face, and a considerably shorter nose.

Given the striking similarity of these $\stackrel{\triangleright}{\circ}$ objective pattern profiles, it seems likely क that the principal diagnostic discrimina- $\overrightarrow{0}$ tors are qualitative features, specifically the tall, furrowed forehead and the long, ${ }_{\stackrel{\omega}{\omega}}$ broad, thickened upper lip, which is so thick that the vermilion border of the upper lip is inverted and angled down. i़ $(\mathcal{F}$ Med Genet 1998;35:920-923)

Keywords: lissencephaly; Miller-Dieker syndrome; ำ pattern profiles

Lissencephaly is a brain malformation charac-o terised by a smooth cerebral surface. The com- $\frac{\Phi}{3}$ plete spectrum includes agyria, mixed agyria/유 pachygyria, pachygyria alone, and a milder malformation known as subcortical band $\vec{\varphi}$ heterotopia.' ${ }^{1}$ Classical (previously type 1)@ lissencephaly ${ }^{2}$ results from an arrest or delay of neuronal migration at about 9 to 13 weeks' gestation. It is observed in Miller-Dieker syndrome (MDS) and isolated lissencephaly» sequence (ILS). Both conditions are associated $\stackrel{\unrhd}{\circledR}$ with deletions involving the LIS1 gene on $\overrightarrow{\overrightarrow{0}}$ chromosome $17 \mathrm{p} 13.3,{ }^{34}$ although there is a今 second X linked locus for ILS. ${ }^{5}$

Visible deletions or other structural rearrangements resulting in deletion are observed in about two-thirds of children with MDS, while large submicroscopic deletions are found 3 in almost all the remainder. ${ }^{6}$ In contrast,
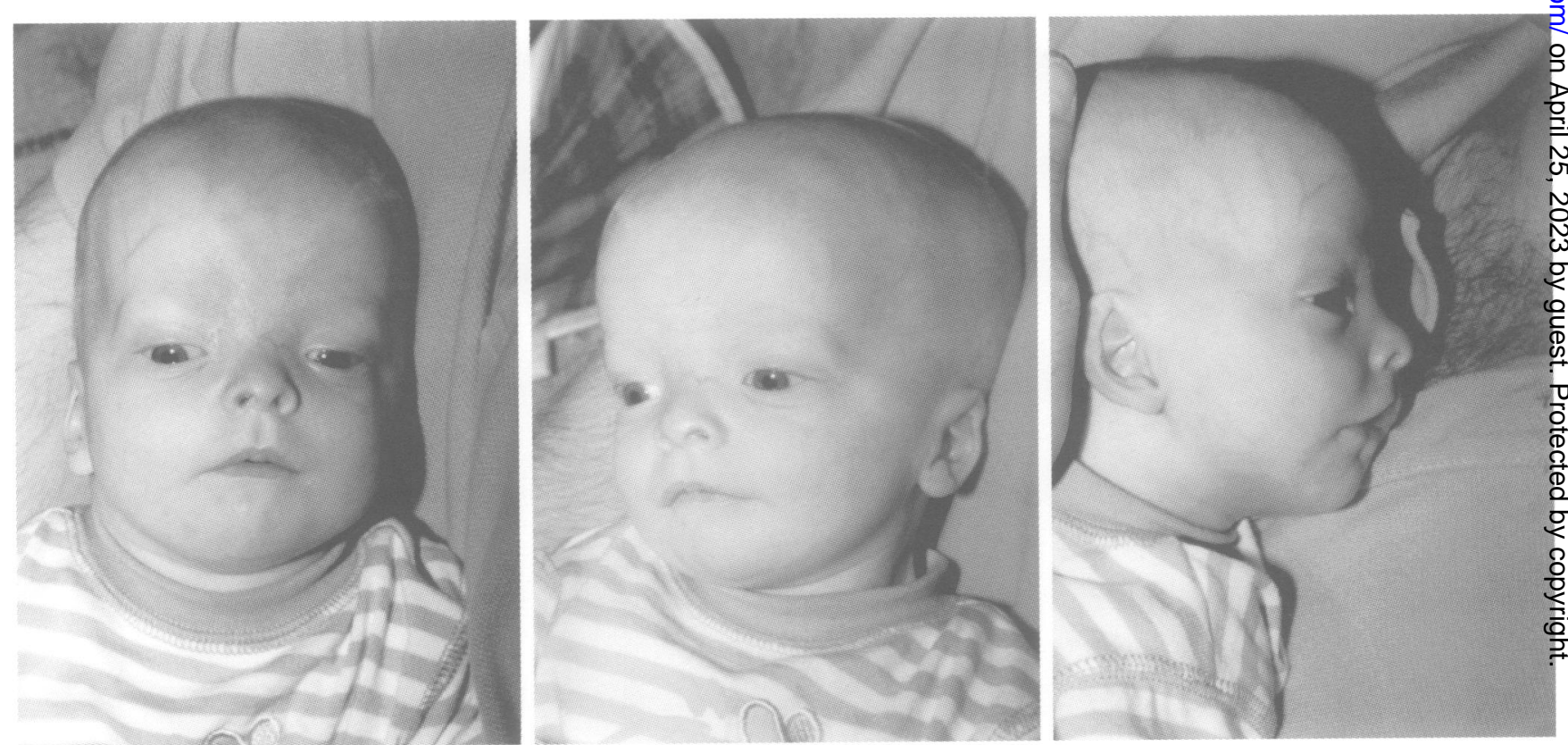

Figure 1 A 3 month old boy with Miller-Dieker syndrome showing the marked thickening of the upper lip, short, upturned nose, tall forehead, and temporal narrowing. (All photographs reproduced with permission.) 


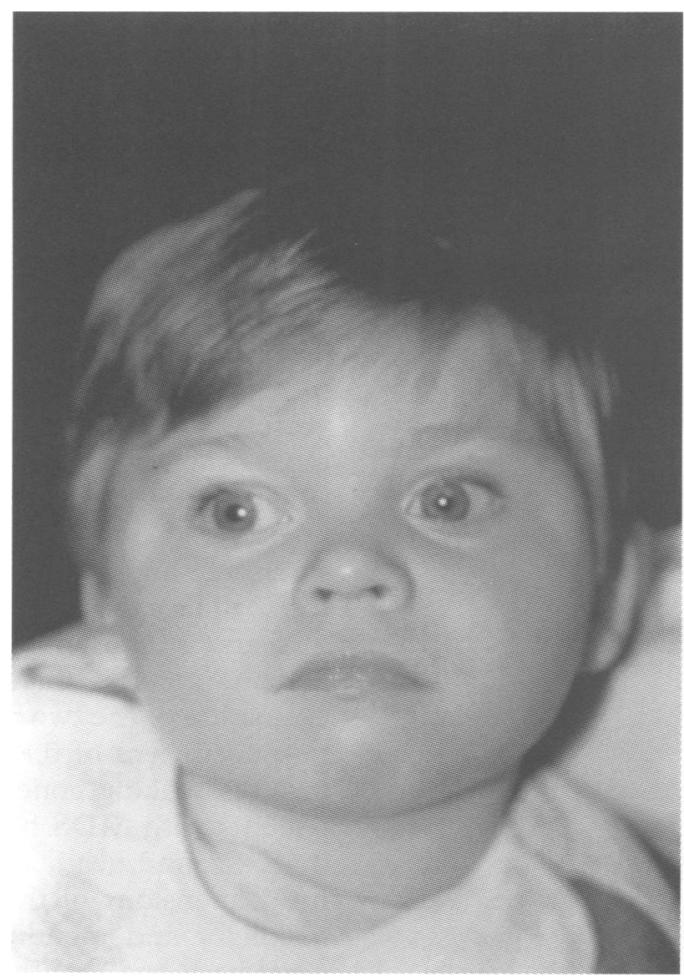

Figure 2 The face in isolated lissencephaly syndrome.

smaller submicroscopic deletions are observed in about $40 \%$ of children with ILS. ${ }^{7}$ Recently, several subjects with ILS have been found to have point mutations within the LIS1 gene. ${ }^{8}$

In MDS (fig 1), lissencephaly is associated with a particular facial appearance, consisting of a tall, prominent forehead, which may show vertical furrowing in up to one quarter of affected patients; bitemporal narrowing; widely spaced eyes with upward slanting palpebral fissures; a markedly short nose with a low bridge, anteverted nares, and flared, thin alae; a long and thick upper lip with rounded philtral pillars and thin, inverted, and downward facing vermilion border; flat midface; small chin; and flattened ear helices. ${ }^{9}$ In contrast, no typical gestalt has been defined in ILS (fig 2).

\section{Material and methods}

We have evaluated five subjects with MDS (aged 3 months to 6 years) and 25 with ILS (aged 1 to 15 years) by clinical examination. In addition, a series of craniofacial measurements was obtained on each subject following the method published by Farkas. ${ }^{10}$ Measurements were recorded to the nearest 0.5 millimetre using GPM sliding and spreading, blunt ended calipers, and a paper metric tape measure. These dimensions were chosen to represent craniofacial widths, lengths, depths, and circumferences plus details of ear, eye, nose, and mouth structure (fig 3). For each dimension, age and sex matched normal standards were available. The population norms were derived from measurements of the head and face in 2326 healthy North American white children and young adults. ${ }^{11}$

Measurements were taken by one of the authors (JEA). The raw data were compared to normal standards and converted to $\mathrm{Z}$ scores to control for age and sex differences. Pattern profiles were compiled for three groups of subjects: ages 6 months to 4 years, 4 to 9 years, and 16 and over. Correlation coefficients and variability indices were generated by the Statistical Package for Social Scientists (SPSS), using the methods published by Garn et al. ${ }^{1213}$

\section{Results}

The first pattern profile divides the 25 subjects with isolated lissencephaly sequence into three age groups: 6 months to 4 years, 4 to 9 years, and 9 to 16 years (fig 4). There is clear similarity of patterns, which is validated by the high
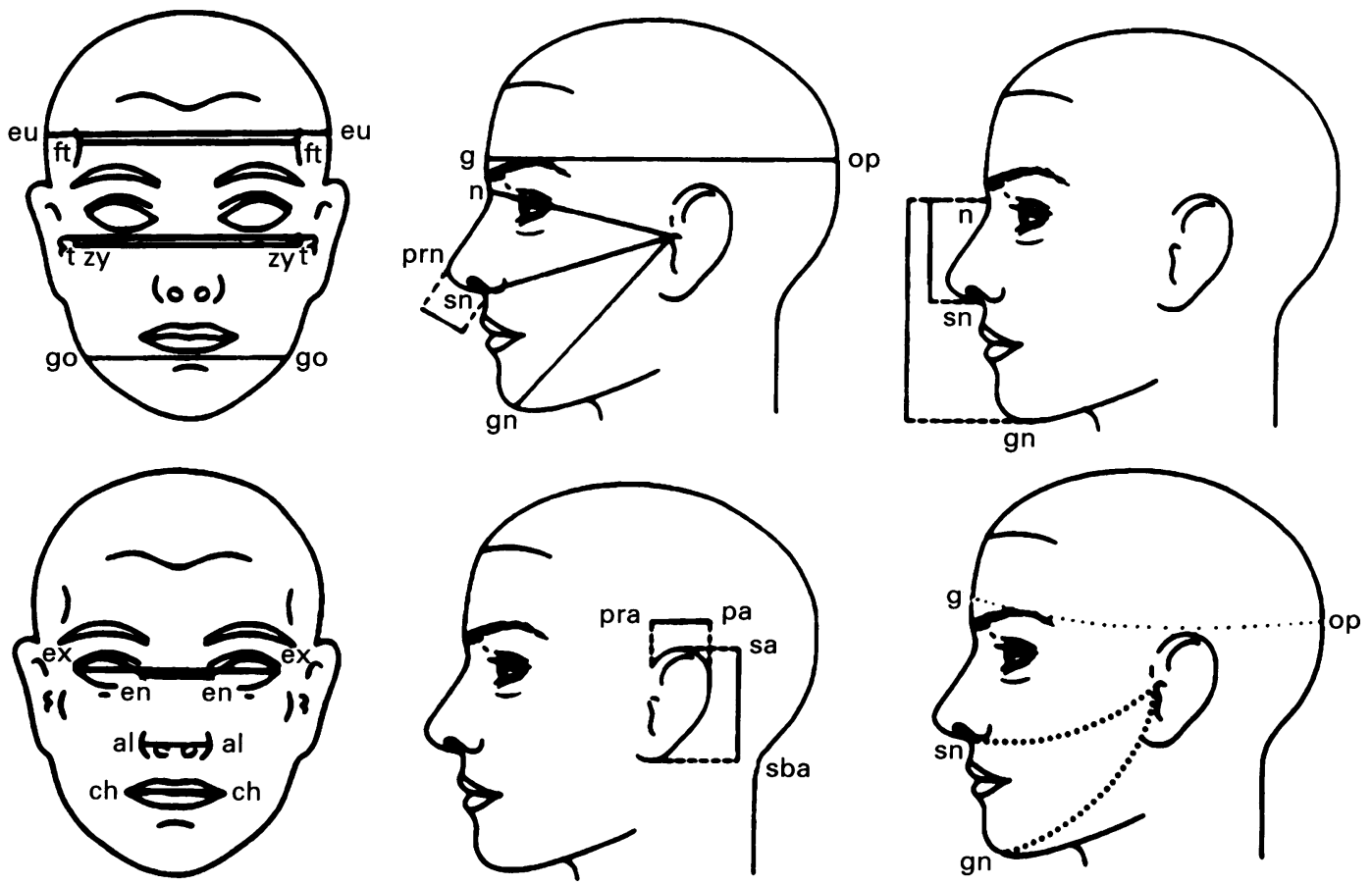

Figure 3 Craniofacial measurements used in this study. Figure adapted from "Anthropometric facial proportions in medicine", by Farkas LG and Munro IR, Charles C Thomas, Springfield, Illinois, 1987, with permission. 
Table 1 Isolated lissencephaly syndrome: age group correlation coefficients

\begin{tabular}{llll}
\hline & 1 & 2 & 3 \\
\hline 1 & 1.000 & $0.7327^{\star \star}$ & $0.5723^{\star}$ \\
2 & $0.7327^{\star \star}$ & 1.000 & $0.8935^{\star \star}$ \\
3 & $0.5723^{\star}$ & $0.8935^{\star \star}$ & 1.000 \\
\hline
\end{tabular}

${ }^{\star} \mathrm{p}<0.01,{ }^{\star \star} \mathrm{p}<0.001$, two tailed significance.

1: 6 months to 4 years; $2: 4$ to 9 years; $3: 16$ years and above.

correlations between age groups 1 and 2 , and between age groups 2 and 3 (two tailed significance $p<0.001$ ). Details of correlation coefficients are shown in table 1 . In all three age groups there is reduced head circumference, head width, and length. Head width and length are reduced to the same extent, so the head is round. Facial depths and heights deviate from normal to a greater extent than facial widths. Facial widths are close to or exceed the mean,

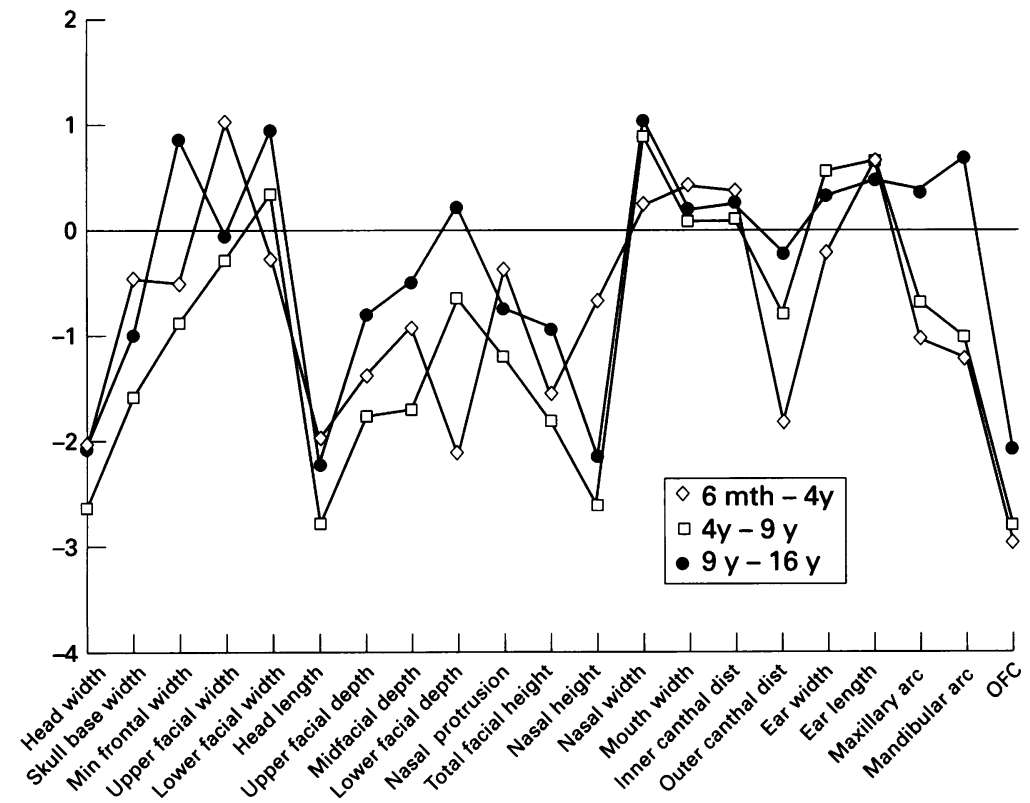

Figure $4 \quad Z$ score pattern profile in ILS: comparison of three age groups, showing marked similarity of patterns, which is borne out by statistical analysis.

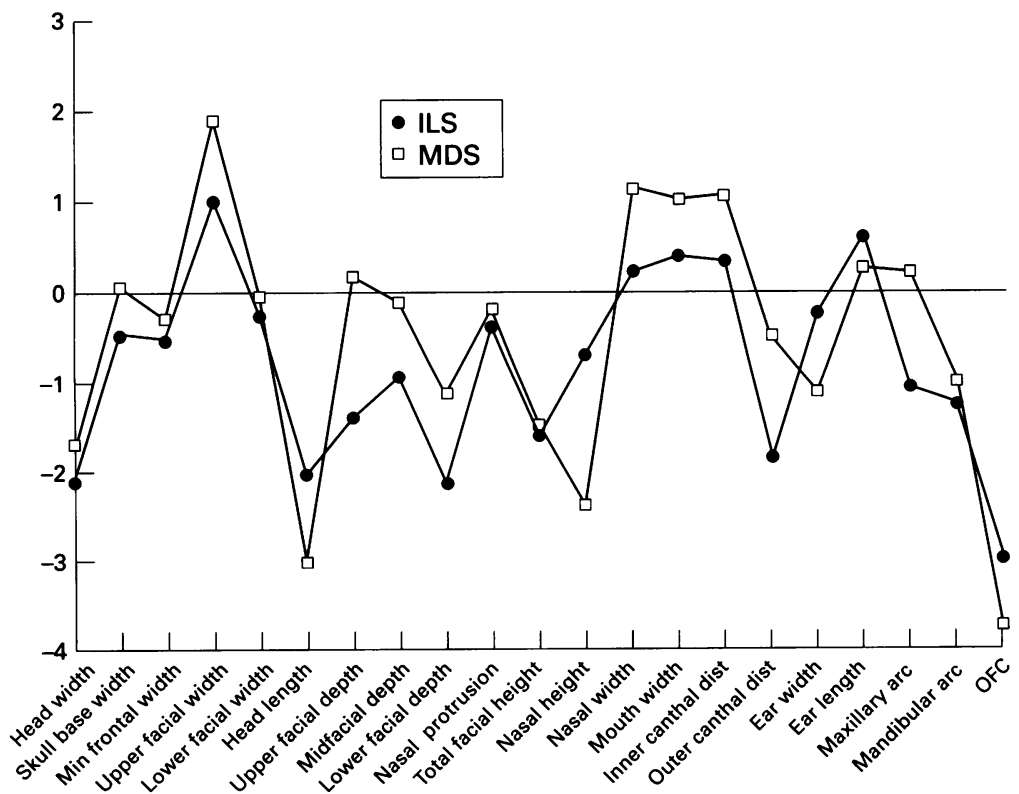

Figure 5 Pattern profile comparing ILS and MDS in age group 1.MDS does show some differences: brachycephaly, markedly short nose, and greater excess of inner canthal distance. while depths and heights are smaller than average. Nose and mouth widths are greater than normal, and those dimensions are particularly significant when taken in the context of small $\frac{\mathrm{D}}{\mathrm{C}}$ head size. Inner canthal distances are greater than normal, whereas outer canthal distances $\Phi$ are reduced, suggesting short palpebral fissure $\stackrel{\oplus}{\oplus}$ length. As age increases, maxillary and mandibular dimensions (width, depth, and arc) $\stackrel{\vec{m}}{\vec{c}}$ become closer to the mean, and some exceed? the mean. In the youngest group, under 4 음 years, the face is wide and short, but it becomes more oval with age.

The second pattern profile shows the unexpected similarities between Miller-Dieker $\overrightarrow{0}$ syndrome and isolated lissencephaly sequence (fig 5). The age group representing 6 months to $\omega$ 4 years is chosen since all but one MDS patients are less than 4 years old. Statisticako evaluation of the two patterns shows a correla- $w$ tion coefficient of $0.812(p<0.001)$ emphasising this striking concordance. In general, the $\overrightarrow{0}$ patients with MDS have brachycephaly rather than a round head, a slightly wider face (firsto five dimensions of the profile), larger depths, maxillary and mandibular arcs, and broader $Z$ nasal base and mouth. Nasal height is considerably shorter and eyes are more widely spaced.

\section{Discussion}

$\mathrm{Z}$ score pattern profile analysis shows craniofacial similarities between Miller-Dieker syndrome (MDS) and isolated lissencephalyo sequence (ILS) which have not been appreci-s ated previously. Microcephaly is common in both, with additional brachycephaly in MDS. $\frac{\text { o }}{8}$ Craniofacial widths are close to, or may exceed, normal, while depths and heights are reduced. Maxillary dimensions are closer to normal than their mandibular counterparts. Width of the mouth and nasal base and inner canthal distances are also above average. In MDS, markedly reduced nasal height and widely: spaced eyes are notable, as expected from sub- 3 . jective assessments. It is likely that qualitative facial differences in MDS, especially the shape $₹$ of the upper lip and furrowing of the forehead,o which are important diagnostic features and serve to distinguish MDS from ILS, would not을 be appreciated in a study of this sort.

This similarity of appearance in MDS and ILS may be the consequence of the underlying ${ }^{\circ}$ structural abnormality of the brain or the $\omega$ shared molecular pathology. We postulate that the presence of lissencephaly leads to a cascade of events which includes poor brain growth (microcephaly), enlargement of the Sylvian fis-sure causing bitemporal narrowing, and fetal ${ }^{\circ}$ hypokinesia causing a small jaw. The more sig-而 nificant compromise in head growth in $\operatorname{MDS}_{\mathbb{\infty}}$ may be associated with the higher likelihood of severe (grade 1 or 2) lissencephaly in MDSe compared to ILS. Grade 1 or 2 lissencephaly iso found in more than $50 \%$ of the children with MDS, but in less than one quarter of those witko ILS (Dobyns, personal communication). It is also possible that LIS1 itself is responsible for some of the shared phenotype since children with $\mathrm{X}$ linked lissencephaly do not have these dysmorphic features (unpublished data). 
When the cohort with ILS is divided by age, it is clear that certain craniofacial dimensions exhibit accelerated growth rates with time. Maxillary and mandibular depths and circumferences, in particular, are closer to the mean and may exceed the mean with increasing age. Total facial height becomes more average while minimal frontal distance exceeds average. Subjectively, these age related changes are seen as a transition from the round face of a young child to a longer, more oval face, with heavy broad brows, at an older age.

Molecular differences between MDS and ILS are beginning to emerge which may eventually explain the craniofacial and cerebral similarities and dissimilarities. Both MDS and IIS are associated with deletions within chromosome band $17 \mathrm{p} 13.3 .^{3}$ Visible deletions or other structural rearrangements resulting in deletion are observed in about two-thirds of children with MDS, while large submicroscopic deletions are found in almost all the remainder. ${ }^{6}$ In contrast, smaller submicroscopic deletions are observed in about $40 \%$ of children with ILS. ${ }^{7}$ The lissencephaly minimal critical region spans approximately 100 to 150 $\mathrm{kb}$ and coincides with the LIS 1 gene, which is orientated $5^{\prime}$ to $3^{\prime}$ from telomere to centromere. ILS translocation breakpoints and partial deletions of LIS1 in ILS and MDS deletion patients strongly suggest that LIS1 is the lissencephaly causative gene. Recently, LIS1 point mutations have been identified in subjects with less severe lissencephaly and intellectual handicap. ${ }^{8}$ Subjective evaluation of these subjects is completely unremarkable. Objective phenotypes have yet to be established.

Complete deletions of LIS1 occur in both ILS and MDS. Deletions extending several hundred kilobases centromeric to the LIS1 gene have been documented in two ILS patients but not in any with MDS. Distal breakpoints of MDS patients are more telomeric than those of ILS patients. These observations are consistent with the concept of an additional gene or genes telomeric to LIS1 contributing to the facial phenotype of MDS and do not support the hypothesis that LIS1 is wholly responsible for the facial dysmorphism seen in MDS.

We are very grateful to the families who took part in the study and the help of the Lissencephaly Network.

1 Dobyns WB, Truwit CL. Lissencephaly and other malformations of cortical development: 1995 update. Neuropediatrics 1995;26:132-47.

2 Dobyns WB, Elias ER, Newlin AC, Pagon RA, Ledbetter Dobyns WB, Elias ER, Newlin AC, Pagon RA, Ledbetter ogy 1992;42:1375-88.

3 Ledbetter SA, Kuwano A, Dobyns WB, Ledbetter DH. Microdeletions of chromosome $17 \mathrm{p} 13$ as a cause of isolated lissencephaly. Am F Hum Genet 1992;50:182-9.

4 Chong SS, Pack SD, Roschke AV, et al. A revision of the lissencephaly and Miller-Dieker syndrome critical regions in chromosome 17p13.3. Hum Mol Genet 1997;6:147-55.

5 Dobyns WB, Andermann E, Andermann F, et al. X-linked malformations of neuronal migration. Neurology 1996;47: malfo

6 Dobyns WB, Reiner O, Carrozzo R, Ledbetter DH Lissencephaly: a human brain malformation associated with deletion of the LIS1 gene located at chromosome 17p13.3. FAMA 1993;270:2838-42.

7 Pilz DT, Macha ME, Precht KS, Dobyns WB, Smith ACM, Ledbetter DH. FISH analysis in 100 patients with isolated lissencephaly sequence (ILS): LIS1 probes significantly increase deletion detection rate. Am $₹$ Hum Genet 1997;61: increase.

8 LoNigro C, Chong SS, Smith ACM, Dobyns WB, Ledbetter DH. Point mutations and an intragenic deletion in LIS 1 , the lissencephaly causative gene, in isolated lissen cephaly sequence and Miller-Dieker syndrome. Hum Mol Genet 1997;6:157-64.

9 Jones KL, Gilbert EF, Kaveggia EG, Opitz JM. The MillerDieker syndrome. Pediatrics 1980;66:277-81.

10 Farkas LG. Anthropometry of the head and face in medicine. New York: Elsevier, 1981.

11 Farkas LG. Anthropometry of the head and face. 2nd ed. New York: Raven Press, 1994

12 Garn SM, Smith BH, Lavelle M. Applications of pattern profile analysis to malformations of the head and face. Radiology 1984;150:683-90.

13 Garn SM, Smith BH, Lavelle M. Quantification of dysmorphogenesis: pattern variability index, $\mathrm{O}_{2} . A m \mathcal{F}$ Radiol 1985;144:365-9. 